\title{
Clinical significance of cardiac murmurs among neonates in non-university units of a tertiary care maternity hospital, Colombo, Sri Lanka
}

\author{
S C Jayawardana ${ }^{1}$, D A Karawita ${ }^{2}$, G de Silva ${ }^{3}$, D Samarasinghe ${ }^{4}$, S Perera ${ }^{4}$
}

Sri Lanka Journal of Child Health, 2015; 44(1): 24-30

\begin{abstract}
Introduction: The complete routine neonatal examination before discharge of the newborn baby is the simplest and earliest way to identify possible heart lesions.
\end{abstract}

Objective: The aim of this study was to ascertain the clinical significance of precordial murmurs heard on routine neonatal examination

Design: Descriptive, cross sectional study design was applied at routine neonatal examination before discharge of the neonate

Method: All consecutive 4,804 live born neonates (excluding those dying before neonatal evaluation) at non-university units of the De Soysa Hospital for Women (DSHW) during a ten month period from 15.05.2013 were screened within 24 hours of birth for precordial murmurs and those with audible murmurs were then referred for echocardiography

Results: Prevalence of murmurs and $\mathrm{CHD}$ at routine neonatal examination was 16 per 1,000 live births and 15 per 1,000 live births respectively. The most common lesions found in echocardiographic evaluation were atrial septal defect $(62 \%)$, patent ductus arteriosus (26\%), ventricular septal defect $(19 \%)$ and cyanotic heart with multiple lesions $(12 \%)$.

Conclusions: At routine neonatal examination, prevalence of murmurs was $1.6 \%$ and the prevalence of CHD was 15 per 1,000 live births. If a murmur was heard, there was a $96 \%$ chance that the neonate could have CHD.

(Key words: Congenital heart disease; neonatal examination; murmur; prevalence; echocardiography)

${ }^{I}$ Acting Paediatrician, De Soysa Maternity Hospital, Colombo, ${ }^{2}$ Consultant Venereologist, Teaching Hospital, Anuradhapura, ${ }^{3}$ Consultant Paediatrician, De Soysa Maternity Hospital, Colombo, ${ }^{4}$ Consultant Paediatric Cardiologist, Lady Ridgeway Hospital Colombo.

(Received on 27 May 2014: Accepted after revision on 23 June 2014)

\section{Introduction}

Congenital heart disease (CHD) is defined as a structural abnormality of the heart or intrathoracic great vessels that is actually or potentially of functional significance ${ }^{1}$. CHD is the leading cause of infant deaths due to birth defects ${ }^{2}$. Incidence of CHD in different studies varies from about 4/1,000 to $50 / 1,000$ live births ${ }^{3}$. CHD can be categorized into 3 groups of lesions based on current knowledge and the severity of the lesions ${ }^{3}$.

1. Severe $C H D$ includes cyanotic $\mathrm{CHD}$ such as dtransposition of the great arteries, tetralogy of Fallot, hypoplastic right heart or left heart, single ventricle (SV), double outlet right ventricle (DORV), truncus arteriosus, total anomalous pulmonary venous connection (TAPVC), critical pulmonary stenosis (PS) and acyanotic CHD such as atrio-ventricular septal defect (AVSD), large ventricular septal defect (VSD), large patent ductus arteriosus (PDA), critical or severe aortic stenosis (AS), severe PS and critical coarctation.

2. Moderate $C H D$ includes mild or moderate AS or aortic incompetence (AI), moderate PS or incompetence, noncritical coarctation, large atrial septal defect (ASD) and complex forms of VSD.

3. Mild CHD includes small VSD, small PDA, mild PS, bicuspid aortic valve (BAV) without AS or AI and small or spontaneously closed ASD.

The complete routine newborn examination is extremely important before discharge of the baby preferably within the first 48 hours of birth to evaluate the readiness for life outside the mother's womb. However, routine neonatal examination fails to detect $44-45 \%$ of babies with CHD from the total prevalence in infancy and more than one third failed to be identified by the 6 week examination ${ }^{4,5}$. Furthermore, if deaths from unrecognized heart diseases are not taken into account, a falsely low picture of the prevalence of serious CHD will be obtained and it has also been revealed that the diagnosis was unrecognized in life in $30 \%$ of all babies dying in infancy from $\mathrm{CHD}^{5}$. The identified prevalence of heart disease causing death in infancy will be greatly influenced by the necropsy rate and the sensitivity of necropsies in detecting cardiovascular malformations ${ }^{5}$. It is probable that 
most of the patients in the severe and moderate CHD groups will be detected in any good medical system.

Studies have identified the differences in the occurrence of CHD among different ethnic groups. Although developed countries have studied their populations on the prevalence, pattern and possible associated risk factors for CHD, studies done in Sri Lanka are scarce in the scientific literature. As Sri Lanka is currently in the early phases of the evolving speciality of paediatric cardiology, it is important to create an evidence base to improve the care given to those with CHD.

\section{Objectives}

1. To ascertain the prevalence and clinical significance of murmurs

2. To ascertain the prevalence and pattern of CHD detected via auscultation at routine neonatal examination carried out prior to discharge from the De Soysa Hospital for Women (DSHW).

\section{Method}

A cross sectional descriptive study was conducted at the De Soysa Hospital for Women (DSHW), Colombo which is a tertiary care hospital and a teaching hospital. During 2013, total admissions and clinic visits were 23,067 and 74,883 respectively $^{6}$. All consecutive live born babies, excluding those who died before neonatal evaluation in the 3 non-university maternity units at DSHW during the ten month period from $15^{\text {th }}$ May 2013 to $15^{\text {th }}$ March 2014 were prospectively taken as the study sample.

All the live born and survived neonates were screened by experienced paediatric house officers using Littman paediatric stethoscope and neonates who were found to have murmurs within 12-24 hours of birth at routine examination were further evaluated by the principal investigator and then referred to the paediatric cardiologist for echocardiography.

Cardiac murmur was defined for this study as a murmur of grade $1 / 6$ in intensity. The intensity of the heart murmur was gauged using the system originally proposed by Levine. Grade 1 refers to a murmur so faint that it can be heard only on listening carefully for some time. A grade 2 murmur is faint, but is immediately audible. Grade 3 refers to a murmur that is moderately loud, and grade 4 to a murmur that is very loud. A grade 5 murmur is extremely loud and is audible with one edge of the stethoscope touching the chest wall. A grade 6 murmur is so loud that it is audible with the stethoscope just removed from contact with the chest wall ${ }^{7}$. Respiratory distress was defined as respiratory rate $>60 / \mathrm{min}$ with chest wall recessions and grunting ${ }^{8}$.

The mean arterial pressure (MAP) is the average pressure during the entire cardiac cycle and integrates the area under the arterial pressure waveform and it is less prone to error ${ }^{9}$. Single MAP measurement was taken when baby was in resting state within the 12-24 hours after birth using a Oscillometric BP monitor. An appropriate-sized BP cuff encircling $75 \%$ or greater of the limb circumference and the length of the cuff at least $2 / 3$ of the length of the upper limb segment were used when taking the measurements. Mean arterial pressure of 31-63 mmHg was taken as the normal ${ }^{10}$. A reading up to $20 \mathrm{mmHg}$ systolic higher in the arm than the leg is normal. If it is $>20 \mathrm{mmHg}$, it is taken as abnormal suggesting coarctation. Wide pulse pressure was defined when the diastolic pressure is less than half of the systolic pressure ${ }^{11}$. Post ductal oxygen saturation was measured over 2 minutes within the 12-24 hours after birth using Nellcor N-3000 pulse oximeter on the foot. Oxygen saturation ( $\mathrm{SaO} 2)$ of $95 \%$ or over was regarded as normal and less than $95 \%$ was taken as low saturation $^{12}$. Period of gestation was calculated by using the mother's last regular menstrual period (LRMP) and in uncertain dates, results of dating scan was used.

Dysmorphology assessment of the neonate was done by history, physical examination of growth parameters, ectodermal features such as skin and hair, skull, face regions and overall face impression, hands and feet, joints and skeleton, and genitals and anus. Those with features suggestive of Down Syndrome (DS) were confirmed by karyotyping.

Details of the neonates with precordial murmurs were taken into a structured data collection sheet which included socio-demographic variables such as maternal age, period of gestation, maturity and the sex of the baby, ethnicity, geographical area, and the variable related to clinical diagnosis and echocardiography screening. The collected data were initially entered into an Ms Excel sheet and then imported to SPSS v 16 for analysis. All the quantitative data were analysed for central tendency and dispersion. Qualitative data were analysed for proportions and percentages. Selected variables were cross tabulated against the presence or absence of CHD and tested for significance using Fishers Exact test to examine the probability (p). This study was designed to meet international ethics guidelines such as informed consent, autonomy, anonymity, confidentiality and data 
security. Ethical clearance was obtained from the Ethics Review Committee of DSHW.

\section{Results}

There were 4,835 live births and 40 stillbirths occurred during the ten month period from $15^{\text {th }}$ May 2013 to $15^{\text {th }}$ March 2014 in the 3 nonuniversity maternity units at DSHW. However, 31 neonates died before the neonatal evaluation in the study. A total of 4,804 neonates were taken as the final sample. Out of the 4,804 neonates, 77 neonates had audible murmur. All these 77 live born neonates and mothers were further analysed for the clinical significance of murmurs and the pattern of CHD. Table 1 depicts findings on routine neonatal examination.

Table 1: Profile of the neonates with murmurs at routine neonatal examination

\begin{tabular}{|c|c|}
\hline Variable & Frequency (\%) $n=77$ \\
\hline $\begin{array}{l}\text { Sex } \\
\text { Male } \\
\text { Female }\end{array}$ & $\begin{array}{l}45(58.4) \\
32(41.6)\end{array}$ \\
\hline $\begin{array}{l}\text { Gestational age(based on POA and dating scan) } \\
<37 \text { weeks } \\
37-42 \text { weeks } \\
>42 \text { weeks }\end{array}$ & $\begin{array}{l}08(10.4) \\
69(89.6) \\
00(0.0) \\
\end{array}$ \\
\hline $\begin{array}{l}\text { Birth weight } \\
>3500 \mathrm{~g} \\
2500-3500 \mathrm{~g} \\
<2500 \mathrm{~g} \text { (Low birth weight) } \\
<1500 \mathrm{~g} \text { (Very low birth weight) } \\
<1000 \mathrm{~g} \text { (Extremely low birth weight) }\end{array}$ & $\begin{array}{l}11(14.3) \\
49(63.6) \\
14(18.2) \\
02(02.6) \\
01(01.3)\end{array}$ \\
\hline $\begin{array}{l}\text { Age at echocardiography } \\
\text { In the } 1^{\text {st }} \text { week } \\
\text { In the } 2^{\text {nd }} \text { week } \\
\text { In the } 3^{\text {rd }} \text { and } 4^{\text {th }} \text { week }\end{array}$ & $\begin{array}{l}61(80.3) \\
10(13.2) \\
05(06.6) \\
\end{array}$ \\
\hline $\begin{array}{l}\text { Grading of murmurs } \\
\text { Grade } 1 \\
\text { Grade } 2 \\
\text { Grade } 3\end{array}$ & $\begin{array}{l}42(54.5) \\
32(41.6) \\
03(03.9)\end{array}$ \\
\hline $\begin{array}{l}\text { Respiratory distress (12-24hours after birth) } \\
\text { No } \\
\text { Yes (Respiratory rate }>60 \text { per min) }\end{array}$ & $\begin{array}{l}50(64.9) \\
27(35.1) \\
\end{array}$ \\
\hline $\begin{array}{l}\text { Mean arterial pressure } \\
\text { Normal } \\
\text { Upper limb }>\text { Lower limb with RF delay } \\
\text { Wide pulse pressure }\end{array}$ & $\begin{array}{l}59(76.6) \\
01(01.3) \\
17(22.1) \\
\end{array}$ \\
\hline $\begin{array}{l}\text { Saturation (12-24 hours after birth) } \\
\text { Normal }(\mathrm{SaO} 2 \geq 95 \%) \\
\text { Low }(\mathrm{SaO} 2<95 \%)\end{array}$ & $\begin{array}{l}71(92.2) \\
06(07.8)\end{array}$ \\
\hline $\begin{array}{l}\text { Predisposing features } \\
\text { Normal appearance } \\
\text { Dysmorphic appearance (by clinical diagnosis) } \\
\text { Trisomy } 21 \text { (diagnosed by karyotype) }\end{array}$ & $\begin{array}{l}69(89.6) \\
04(05.2) \\
04(05.2)\end{array}$ \\
\hline
\end{tabular}

Maternal profile shows that the mean maternal age is 29.1 years and it varied from 18 to 43 years. Median and standard deviation were 28 years and
5.6 years respectively. Other maternal characteristics are shown in table 2 . 
Table 2: Maternal profile of the neonates with precordial murmurs

\begin{tabular}{|l|c|}
\hline \multicolumn{1}{|c|}{ Variable } & Frequency (\%) \\
\hline Maternal age in years & $02(02.6)$ \\
$20-19$ & $18(23.4)$ \\
$25-29$ & $22(28.6)$ \\
$30-34$ & $19(24.7)$ \\
$35-39$ & $13(16.9)$ \\
$40-44$ & $03(03.9)$ \\
\hline Maternal complications & \\
No complications & $49(63.6)$ \\
Diabetes mellitus & $09(11.7)$ \\
Gestational diabetes mellitus (DM) & $09(11.7)$ \\
Maternal Heart Disease & $05(06.5)$ \\
Pregnancy Induced Hypertension (PIH) & $02(02.6)$ \\
Gestational DM and PIH & $02(02.6)$ \\
Psychiatric illness & $01(01.3)$ \\
\hline
\end{tabular}

The prevalence of murmurs among neonates on routine neonatal examination in this urban maternal hospital in Sri Lanka was 1.6\% (16 per 1,000 live births). Prevalence of CHD was 15 per 1,000 live births at routine neonatal examination. The clinical significance of murmurs shows that, if a murmur is heard there is $96 \%$ chance that the neonate could have an underlying structural lesion. All neonatal murmurs detected in the study were either grade 1, 2 or 3 . Most of the mild congenital heart lesions, as expected, had grade 1 murmurs (42\%). Finding a grade 1 or 2 murmur identified about $96 \%$ of cardiac lesions in the study. However, there is no relation between the intensity of the murmur versus the presence of CHD $(\mathrm{p}=0.880)$ (Table 3$)$.

Table 3: Grading of the murmurs vs. type of heart lesions

\begin{tabular}{|c|c|c|c|c|c|c|}
\hline \multirow{2}{*}{$\begin{array}{c}\text { Grading } \\
\text { of the } \\
\text { murmur }\end{array}$} & \multicolumn{5}{|c|}{ Type of heart lesion } & \multicolumn{2}{|c|}{\begin{tabular}{c} 
Congenital heart disease absent \\
\cline { 2 - 6 }
\end{tabular}} & $\begin{array}{c}\text { Congenital heart disease present } \\
\text { CHD } \\
\text { (percent) }\end{array}$ & $\begin{array}{c}\text { Moderate } \\
\text { CHD } \\
\text { (percent) }\end{array}$ & $\begin{array}{c}\text { Mild } \\
\text { CHD } \\
\text { (percent) }\end{array}$ & $\begin{array}{c}\text { Normal } \\
\text { (percent) }\end{array}$ & $\begin{array}{c}\text { Diabetic } \\
\text { Cardiomyopathy } \\
\text { (percent) }\end{array}$ & $\begin{array}{c}\text { Total } \\
\text { (percent) }\end{array}$ \\
\hline 1 & $03(03.9)$ & $05(06.5)$ & $32(41.6)$ & $01(01.3 \%)$ & $01(01.3 \%)$ & $42(54.5)$ \\
\hline 2 & $11(14.3)$ & $10(13.0)$ & $10(13.0)$ & $00(0.0 \%)$ & $01(01.3 \%)$ & $32(41.6)$ \\
\hline 3 & $01(01.3)$ & $01(01.3)$ & $01(01.3)$ & $00(0.0 \%)$ & $00(0.0 \%)$ & $03(03.9)$ \\
\hline Total & $15(19.5)$ & $16(20.8)$ & $43(55.8)$ & $01(01.3 \%)$ & $02(02.6 \%)$ & $77(100.0)$ \\
\hline
\end{tabular}

The prevalence and pattern of $\mathrm{CHD}$ at routine neonatal examination showed that $92 \%(71 / 77)$ of lesions were acyanotic lesions, only $8 \%(6 / 77)$ having cyanotic lesions. Over half of the neonates (56\%) with murmurs had mild CHD. Features of isolated diabetic cardiomyopathy were found in 2 patients $(2.6 \%)$. (Table 3$)$
It is hard to find isolated lesions and most of the cardiac lesions have multiple echocardiographic abnormalities. The most common lesions found on echocardiographic evaluation of the newborn with murmurs were ASD (62\%), PDA (26.0\%), VSD $(19.5 \%)$, and cyanotic heart with multiple lesions $(11.75 \%)$. Tetralogy of Fallot was not found in this study setting. The features of diabetic 
cardiomyopathy were found in $9.1 \%$ of neonates with murmurs. (Table 4)

Table 4: Lesions found on echocardiography

\begin{tabular}{|l|c|}
\hline Major category of lesion & Frequency (\%) \\
\hline Atrial septal defect & $48(62.3)$ \\
\hline Ventricular septal defect & $15(19.5)$ \\
\hline Patent ductus arteriosus & $20(26.0)$ \\
\hline Diabetic cardiomyopathy & $07(09.1)$ \\
\hline Hypoplastic arch & $01(01.3)$ \\
\hline $\begin{array}{l}\text { Atrio-ventricular septal } \\
\text { defect }\end{array}$ & $01(01.3)$ \\
\hline Coarctation & $01(01.3)$ \\
\hline $\begin{array}{l}\text { Cyanotic heart with } \\
\text { multiple lesions }\end{array}$ & $09(11.7)$ \\
\hline $\begin{array}{l}\text { Mild branch pulmonary } \\
\text { artery stenosis }\end{array}$ & $01(01.3)$ \\
\hline Normal heart & $01(01.3)$ \\
\hline Small arch & $02(02.6)$ \\
\hline
\end{tabular}

\section{Discussion}

Identification of precordial murmurs during routine neonatal examination is not the only way to screen newborns for possible CHD. However, it is the most common, widely and readily available way to screen for CHD among neonates. This DSHW study mainly looked at the significance of the auscultatory findings in routine neonatal examination which is usually performed within 24 hours after birth. This study was limited to the 4,804 live born neonates after excluding 31 neonates who died before the completion of the neonatal evaluation and their autopsy findings were also not available and this was one of the limitations of the study. It was also not studied what fraction of neonates spontaneously resolved, outcome of subsequent interventions and the number that went through the nature's benign course because of the limitation of the study design selected.

Among 4,804 live born neonates the prevalence of murmurs was 16 per 1,000 live births. In other words, $1.6 \%$ of live born neonates had an audible murmur and out of this $96 \%$ had CHD. Therefore, the prevalence of CHD was 15 per 1,000 live births among neonates identified by precordial auscultation. If a murmur is heard, there is a $96 \%$ chance of an underlying cardiac malformation. The intensity of the murmur was not related to the presence or absence of CHD.

Neonatal examination detects only $44-45 \%$ of cardiac malformations which present in infancy ${ }^{4,13}$.
Thus, over half of CHD found in infancy are missed at routine neonatal examination ${ }^{4}$. Most studies are institutional and will not reflect true prevalence in the general population. This DSHW study was limited to live born neonates and did not include stillbirths or autopsy findings and the study's main focus was on the clinical significance of precordial murmurs heard during the routine neonatal examination.

Previous studies have shown that $0.6-60 \%$ of neonates have a murmur at some stage, and more recent studies have shown that $0.6-1.6 \%$ (6-16 per 1,000 live births) of babies have a murmur at the routine neonatal examination ${ }^{14}$. The prevalence of murmurs in this study also remains within the range of recent studies. An Iranian study, within 24 hour neonatal examination among 2,928 neonates had revealed the prevalence of murmurs as 31 per 1,000 live births. Furthermore, the same study had shown that the prevalence of cardiovascular malformations as 16 per 1,000 live births ${ }^{15}$.

In a Dhaka, Bangladesh study, $68 \%$ of neonates with cardiac murmurs were found to have structural heart defects ${ }^{16}$. A two year prospective study among 7,204 newborn babies concluded that neonatal examination detects only $44 \%$ of cardiac malformations which present in infancy. The same study further explained that if a murmur is heard there is a $54 \%$ chance of there being an underlying cardiac malformation ${ }^{16}$. In a study done at Tokyo Medical University, out of 5,124 neonates, prevalence of murmur was 22 per 1,000 live births and the prevalence of CHD was 14 per 1,000 live births ${ }^{17}$. In a Pakistan study, the incidence of congenital heart disease was 15 per 1,000 live born neonates at 12 hours of life ${ }^{18}$. Beijing Congenital Malformation Registry study had shown that the prevalence of CHD as 6.7 per 1,000 live births ${ }^{19}$. The Baltimore-Washington Infant study showed that the prevalence of CHD in 2.4 per 1,000 live births ${ }^{20}$. However, these different values and values in this study are not comparable due to the methodological and study setting differences.

Most cardiac lesions (46\%) have multiple structural abnormalities. The most common lesions found on echocardiographic evaluation of the newborn with murmurs were ASD (62\%), PDA $(26.0 \%)$, VSD $(19.5 \%)$, and cyanotic heart with multiple structural lesions $(11.75 \%)$. The features of diabetic cardiomyopathy were found in $9.1 \%$ of neonates with murmurs. Regional studies in North India ${ }^{16}$, Mysore $^{23}$, Pakistan ${ }^{18}$, Iran ${ }^{21}$ and Beijing ${ }^{19}$ have also shown ASD, VSD and PDA as common lesions but in variable proportions. Although regional studies report the prevalence of Tetralogy of Fallot (TOF), this sample did not have single case of TOF. 


\section{Conclusions}

- The prevalence of murmurs among neonates on routine neonatal examination in the nonuniversity units of DSHW was 1.6\% (16 per 1,000 live births).

- Prevalence of CHD detected via auscultation at routine neonatal examination carried out prior to discharge from DSHW was 15 per 1,000 live births.

- If a murmur was heard on routine neonatal examination, there was a $96 \%$ chance that the neonate could have a CHD.

Multiple structural abnormalities were found in $46 \%$ of neonates with murmurs. The rest had isolated lesions or single structural lesion and the most common single lesions were ASD (36\%), PDA (10\%), and VSD (4\%). However, when considering the mutually non-exclusive percentages; the most common lesions of neonates with murmurs were ASD (62\%), PDA (26.0\%), VSD $(20 \%)$, and cyanotic heart with multiple lesions $(12 \%)$. Tetralogy of Fallot was not found among these lesions as opposed to most of the regional studies. The features of diabetic cardiomyopathy were found in substantial number of neonates $(9 \%)$.

\section{References}

1. Mitchell SC, Korones SB, Berendes HW. Congenital heart disease in 56,109 births: Incidence and natural history. Circulation 1971; 43(3): 323-32 http://dx.doi.org/10.1161/01.CIR.43.3.323

2. Wen SW, Liu S, Joseph K, Rouleau J, Allen A. Pattern of infant mortality caused by major congenital anomalies. Teratology 2000; 61(5): 342-6.

http://dx.doi.org/10.1002/(SICI)10969926(200

005)61:5<342::AID-TERA5>3.0.CO;2-7

3. Hoffman JIE, Kaplan S. The incidence of congenital heart disease. Journal of the American College of Cardiology 2002; 39(12): 1890-900.

http://dx.doi.org/10.1016/S07351097(02)0188 $\underline{6-7}$

4. Wren C, Richmond S, Donaldson L. Presentation of congenital heart disease in infancy: implications for routine examination. Archives of Disease in Childhood Fetal and Neonatal Edition 1999; 80(1): F49-F53. http://dx.doi.org/10.1136/fn.80.1.F49
5. Abu-Harb M, Hay E, Wren C. Death in infancy from unrecognized congenital heart disease. Archives of Disease in Childhood 1994; 71:3-7.

http://dx.doi.org/10.1136/adc.71.1.3

6. De Soysa Maternity Hospital (DMH). Annual Report of the. Colombo: 2014.

7. Silverman ME, Wooley CF, Samuel A. Levine and the history of grading systolic murmur. American Journal of Cardiology 2008; 102(8): 1107-10. http://dx.doi.org/10.1016/i.amjcard.2008.06.02 $\underline{7}$

8. Kliegman RM, Behrman RE, Jenson HB, Stanton BF, editors. Nelson Textbook of Pediatrics. 18th ed. Philadelphia: Saunders; 2007.

9. Andria D, Stebor RN. Basic principal of noninvasive blood pressure measurements in infants. Advances in Neonatal Care. 2005; 5(5): 252-61. http://dx.doi.org/10.1016/j.adnc.2005.06.005

10. Kent AL, Kecskes Z, Shadbolt B, Falk MC. Normative blood pressure data in the early neonatal period. Pediatric Nephrology. 2007; 22(9): 1335-41. http://dx.doi.org/10.1007/s00467-007-0480-8

11. McIntosh N, Helms PJ, Smyth RL, Editors.. Forfar \& Arneil's textbook of Pediatrics. 6th ed. Edinburgh; Churchill Livingstone: 2003. p. 270-2.

12. Richmond S, Reay G, Abu Harb M. Routine pulse oximetry in the asymptomatic newborn. Archives of Disease in Childhood Fetal and Neonatal Edition 2002; 87: p. F83-F88. http://dx.doi.org/10.1136/fn.87.2.F83

13. Ainsworth SB, Wyllie JP, Wren C. Prevalence and clinical significance of cardiac murmurs in neonates. Archives of Disease in Childhood Fetal and Neonatal Edition 1999; 80(1): F4347.

http://dx.doi.org/10.1136/fn.87.2.F83

14. Farrer KFM, Rennie JM. Neonatal murmurs: are senior house offcers good enough? Archives of Disease in Childhood Fetal and Neonatal Edition 2003; 88: F147-F151 http://dx.doi.org/10.1136/fn.88.2.F147 
15. Mehrdad M, Hakimeh S, Hosein D, Rogaeh A, Khatereh I, Afsaneh E. Heart murmur in neonates: How often is it caused by congenital heart disease? Iranian Journal of Pediatrics 2011; 21(1):103-6.

16. Hossain MM, Hasan MN, Shirin M, Mamun MA, Hossain MDD. Bangladesh Journal of Child Health 2010; 34(2): 56-61.

17. Takami T, Kawashima H, Kamikawa A, Nemoto S, Takei Y, Miyajima T, Hoshika A. Prevalence of cardiac murmur detected on routine neonatal examination. Journal of Tokyo Medical University 2001; 59(4):290-3.

18. Hussain S, Sabir MU, Afzal M, Asghar I. Incidence of congential heart disease among neonates in a neonatal unit of a tertiary care hospital. Journal of the Pakistan Medical Association 2014; 64(2):175-8

19. Yang Xue-yong, LI Xiao-feng, LU Xiao-dong, LIU Ying-long. Incidence of congenital heart disease in Beijing, China. Chinese Medical Journal 2009; 122(10): 1128-32.
20. Ferencz C, Rubin JD, McCarter RJ, Brenner JI, Neill CA et al. Congenital heart disease: prevalence at live birth. The BaltimoreWashington Infant Study. American Journal of Epidemiology 1985; 121(1):31-36.

21. Nikyar B, Sedehi M, Mirfazeli A, Qorbani M, Golalipour MJ. Prevalence and pattern of congenital heart disease among neonates in Gorgan, Northern Iran (2007-2008). Iran Journal of Pediatrics 2011; 21(3): 307-12.

22. Kapoor R, Gupta S.. Prevalence of congenital heart disease, Kanpur, India. Indian Pediatrics. 2008; 45(4): 309-11.

23. Samitha R, Karat SC, Narayanappa D, Krishnamurthy B, Prasanth SN, Ramachandra NB. Prevalence of congenital heart diseases in Mysore. Indian Journal of Human Genetics 2006; 12: 11-16.

http://dx.doi.org/10.4103/0971-6866.25296 